Jurnal Jurnal Kepelatihan Olahraga, Universitas Pendidikan Indonesia Kepelatihan

Olahraga

Journal homepage: http://ejournal.upi.edu/index.php/JKO

Volume, 12. No, 2. September 2020

p-ISSN: 2086-339X / e-ISSN: 2657-1765

\title{
Pengaruh SAH (Sport Active Hijab) dalam Mempertahankan Tingkat Termoregulasi dan Hidrasi Tubuh Setelah Olahraga
}

\author{
Lulu Meilita $^{1 *}$,Berliana ${ }^{2}$ \\ ${ }^{1}$ Pendidikan Kepelatihan Olahraga, Fakultas Pendidikan Olahraga dan Kesehatan, Universitas \\ Pendidikan Indonesia, Bandung, Indonesia \\ ${ }^{2}$ Pendidikan Olahraga, Sekolah Pascasarjana Universitas Pendidikan Indonesia, Bandung, Indonesia \\ *Correspondence: E-mail: lulumeilita9@gmail
}

\begin{abstract}
A B S T R A C T S
Research carried out related to the use of the jilbab when exercising is considered dangerous the effect is overterm and dehydration.The main purpose of this research is to find out the effect of Sport Active Hijab in maintaining the level of thermoregulation and body hydration after exercise.Innovations made by researchers, the jilbab with Italian Lycra, Spandex Balloons and Poly-Spandex function as controllers of the body's thermoregulation and hydration levels. The research method used is experimental with a pretest posttest group design. The population in this reasearch is colleger of PKO, FPOK UPI. The sampling technique in this research is purposive sampling, with 15 colleger according to the criteria. Divided into three groups using the Random Assignment method. The instruments used is digital thermometer and PURI, hydration measurements based on urine color chart. Based on the results of this research show that the design D3 can maintain the level of thermoregulation and hydration of the body after exercise with lycra fabrics.The results of this reasearch can be used by female athletes as a jilbab choice and designers can used as a development of jilbab design so that female athletes will remain safe and comfortable when wearing jilbab in their training.
\end{abstract}

(C) 2019 Tim Pengembang Jurnal Kepelatihan Olahraga

A B S T R A K

Penelitian yang dilakukan berkaitan dengan penggunaan jilbab ketika olahraga yang dianggap dapat membahayakan karena menyebabkan overterm dan dehidrasi. Tujuan utama penelitian ini adalah untuk mengetahui pengaruh Sport Active Hijab dalam mempertahankan tingkat termoregulasi dan hidrasi tubuh setelah olahraga. Inovasi yang dibuat oleh peneliti, jilbab dengan bahan Italian Lycra, Spandex Balon dan Poly-Spandex berfungsi sebagai controllers tingkat termoregulasi dan hidrasi tubuh. Metode penelitian yang digunakan adalah eksperimen dengan desain penelitian pretest postest grup design. Populasi pada penelitian ini adalah mahasiswa PKO, FPOK UPI. Teknik sampling yang digunakan pada penelitian ini adalah purposive sampling, dengan jumlah 15 mahasiswa sesuai kriteria penelitian. Dibagi kedalam 3 kelompok menggunakan metode Random Assigment. Instrumen yang digunakan adalah termometer digital dan PURI, pengukuran hidrasi berdasarkan chart warna urin. Berdasarkan hasil penelitian menunjukan bahwa desain yang dapat mempertahankan tingkat termoregulasi dan hidrasi tubuh setelah olahraga adalah desain D3 dengan bahan lycra.Hasil dari penelitian ini dapat dipakai oleh para olahragawan wanita sebagai pilihan jilbab yang dapat digunakan dan dijadikan sebagai pengembangan desain jilbab oleh designer sehingga para olahragawan wanita akan tetap aman dan nyaman ketika memakai jilbab dalam pelatihannya.

\begin{tabular}{l}
\hline \multicolumn{1}{c}{ A R T I C L E I N F O } \\
\hline Article History: \\
Received 24 July 2020 \\
Revised 27 July 2020 \\
Accepted 31 August 2020 \\
Available online 5 September \\
2020 \\
\hline Keyword: \\
Sport Active Hijab, \\
hijab, \\
thermoregulation, \\
hydration.
\end{tabular}

\begin{tabular}{l}
\hline \multicolumn{1}{c}{ I N F O A R T I K E L } \\
\hline Riwayat Artikel: \\
Diterima 24 Juli 2020 \\
Direvisi 27 Juli 2020 \\
Diterima 31 Agustus 2020 \\
Tersedia online 5 September \\
2020 \\
\hline Kata Kunci: \\
Sport Active Hijab, \\
Jilbab, \\
Termoregulasi, \\
Hidrasi. \\
\end{tabular}




\section{PENDAHULUAN}

Penggunaan jilbab dalam olahraga dewasa ini sudah bergeser ke arah trendmode untuk para wanita. Dalam tinjauan olahraga jilbab masih dianggap membahayakan aktivitas olahraga terutama oleh seorang atlet. Seperti yang di nyatakan dalam media masa jilbab dapat dimanfaatkan lawan untuk mencekik leher dan dapat berakibat fatal bagi atlet (tirto.id, 2018).

Kemampuan pakaian dalam menyerap keringat dan penguapan tergantung pada permeabilitas udara dan uap air dari pakaian tersebut. Permeabilitas udara adalah porositas atau kemudahan udara melewati materi. Permeabilitas udara menentukan faktor-faktor seperti perlawanan angin kain layar, hambatan udara kain parasut, dan efektivitas berbagai jenis filter udara. Hal ini juga mempengaruhi kehangatan atau kesejukan kain. Permeabilitas uap air adalah ukuran untuk breathability atau kemampuan tekstil untuk mentransfer kelembaban sehingga semakin tinggi permeabilitas uap air suatu pakaian maka semakin tinggi pula kemampuannya dalam menyerap keringat. Kondisi ini menguntungkan pada saat olahraga karena dengan kemampuan dalam menyerap keringat maka dapat menurunkan core dan skin temperature dengan cepat (Faradilla \& Putrianto, 2018). Dalam pemakaian bahan sportwear (pakaian olahraga) bisa menjadi pemicu terjadinya dehidrasi dan meningkatnya termoregulasi tubuh.

Mekanisme pelepasan panas sangat penting dalam aktivitas fisik, ketika kita berolahraga produksi panas dapat mencapai 120F setiap 5 menit yang berarti cairan tubuh kita dapat benar-benar mendidih. Jika panas tidak dilepaskan, tubuh dapat melepaskan panas melalui radiasi, konduksi, konveksi dan penguapan.(Van Rosendal, Osborne, Fassett, \& Coombes, 2009). Penguapan panas, pengaturan suhu tubuh dan produksi keringat yang terkait dengan kinerja olahraga sebenarnya lebih ditentukan oleh intensitas atau durasi olahraga, suhu lingkungan, kelembaban dan ketebalan kulit(Toffoletti \& Palmer, 2017) . Latihan fisik secara teratur dalam waktu cukup lama yaitu kurang lebih 30 menit dapat menyebabkan perubahan terhadap fungsi tubuh yaitu tekanan darah dan frekuensi denyut nadi istirahat (Ashadi, 2017).

Selain itu dalam perubahan fungsi tubuh saat "... latihan fisik dengan intensitas berat selama 20 menit akan meningkatkan suhu tubuh dari $37{ }^{\circ} \mathrm{C}$ menjadi $40^{\circ} \mathrm{C}$..." (Bompa \& TO, 2015). Suhu tubuh saat latihan atau aktivitas fisik juga dipengaruhi oleh suhu lingkungan, kelembaban udara, kecepatan angin, jenis pakaian yang dipakai, sumber panas, serta waktu paparan panas (Sandi, 2011).

Termoregulasi merupakan salah satu hal penting dalam homeostatis. Termoregulasi adalah proses yang melibatkan mekanisme homeostatik yang mempertahankan suhu tubuh dalam kisaran normal, yang dicapai dengan mempertahankan keseimbangan antara panas yang dihasilkan dalam tubuh dan panas yang dikeluarkan (Brooks, Hittelman, Faulkner, \& Beyer, 2014). Evaporasi yang berfungsi menjaga suhu tubuh agar tetap konstan dan modifikasi sistem sirkulasi dibagian kulit. Kontraksi pembuluh darah di bagian kulit dan counter current heat exchange adalah salah satu cara untuk mengurangi kehilangan panas tubuh.

Sistem termoregulasi dikendalikan oleh hipotalamus di otak, yang berfungsi sebagai termostat tubuh. Hipotalamus sebagai pusat integrasi termoregulasi tubuh, menerima informasi aferen mengenai suhu di berbagai bagian tubuh dan memulai penyesuaianpenyesuaian terkoordinasi yang sangat rumit dalam mekanisme penambahan atau pengurangan panas sesuai dengan keperluan untuk mengkoreksi setiap penyimpangan suhu inti dari "patokan normal" (Frank E. Marino, 2008). Tubuh dapat membiarkan perubahan kecil pada suhu tubuh, akan tetapi bila penyimpangan terjadi antara $4^{\circ} \mathrm{C}$ sampai $5^{\circ} \mathrm{C}$ dari keadaan 
normal $37^{\circ} \mathrm{C}$ biasanya disertai dengan kerusakan yang menetap pada sistem saraf atau bahkan menyebabkan kematian (Kukus, Supit, \& Lintong, 2013).

Kehilangan cairan tubuh dan elektrolit pada saat berolahraga menyebabkan dehirasi yang dapat mengganggu penampilan fisik dalam olahraga cairan tubuh dan elektrolit berkurang. Kehilangan cairan tubuh dan elektrolit pada saat berolahraga menyebabkan dehirasi yang dapat mengganggu penampilan fisik dalam olahraga (Van Rosendal et al., 2009). Kehilangan cairan tubuh yang berlebihan dapat berakibat fatal terhadap kinerja fungsi tubuh, yang tentunya harus segera dikembalikan ke tingkat sebelumnya (rehidrasi) (Sandi, 2011). Kehilangan cairan tubuh ini dapat mempengaruhi penampilan fisik, memperberat kerja jantung, dan dapat menyebabkan kematian (Departmen of Healt Statistik and Informatics World Health Organization, 2011).

Kehilangan cairan melalui pernafasan (sekitar 350ml), melalui penguapan pada kulit $(100 \mathrm{ml})$ dan melalui keringat $(350 \mathrm{ml})$, atau melalui ginjal dalam bentuk air seni (10002000ml, sekitar 900ml mutlak diperlukan untuk membuang partikel-partikel yang tidak diperlukan. Sejumlah air (sekitar 150-200ml, bukan diare) juga hilang melalui feses. Dehidrasi derajat ringan-sedang ditandai dengan rasa haus, sakit kepala, kelelahan, wajah memerah, mulut dan kerongkongan kering. Dehidrasi ringan ini merupakan dehidrasi yang terjadi dalam jangka waktu pendek dan tidak terlalu parah tetapi apabila dibiarkan maka akan berdampak buruk bagi kesehatan tubuh.

Ada lima metode pengukuran status hidrasi yang mampu dan sering digunakan yaitu penurunan berat badan, berat jenis urin, volume urin 24 jam, warna urin, dan rasa haus. Metode penurunan berat badan lebih cocok digunakan pada subyek yang mengalami kurang air tubuh mendadak atau akut (olahraga sedang/berat dan muntah/diare). Pengukuran volume urin 24 jam lebihsesuai diterapkan pada subyek pasien rawat inap. Metode rasa haus sangat subjektif dan dipengaruhi umur. Rasa haus muncul setelah tubuh mengalami kurang air sekitar 0,5\%
(Hasibuan et al., 2018). Metode warna urin menggunakan nomor skala yang menunjukkan rentang warna urin mulai dari jernih dengan skala 1 hingga yang pekat (coklat kehijauan) dengan skala 8 (S. M. Shirreffs, 2017).

Pada iklim panas, pakaian berfungsi untuk menjaga tubuh dari paparan sinar matahari atau berbagai dampak lainnya, sedangkan di iklim dingin sifat insulasi termal pakaian penting untuk menjaga tubuh agar tetap hangat. Pakaian bertindak sebagai penghalang yang menghambat penguapan serta mengurangi kehilangan panas tubuh dengan mengurangi sirkulasi udara di dekat kulit (Mo'einfard, 2001). Penyebaran panas (thermal) dan kelembaban/uap air melalui pakaian melibatkan proses penguapan, kondensasi, penyerapan, dan desorpsi. Pakaian bertindak sebagai penghalang yang menghambat penguapan sehingga pakaian yang memiliki kemampuan penguapan yang baik akan menguntungkan pada saat melakukan berolahraga. Penelitian yang dilakukan pada tekstil menunjukkan bahwa kenyamanan ditentukan oleh jenis dan ketebalan kain (Kim \& $\mathrm{Na}$, 2014). Pakaian dapat mempengaruhi produksi keringat karena sifat kainnya, seperti wol atau pakaian yang terdiri dari banyak lapisan (Kane, Mishra, \& Dutta, 2016). Atlet wanita dapat mengenakan perlengkapan olahraga Muslim yang tepat dari polyester dan menggunakannya dalam satu lapisan sehingga tidak akan mempengaruhi produksi keringat atau penguapan.

Menurut hukum dan kebiasaan Islam, wanita Muslim dilarang mengenakan pakaian olahraga yang menunjukkan tubuh mereka kecuali wajah dan tangan. Untuk melakukan aktivitas olahraga, sebagian besar wanita Muslim mengenakan pakaian olahraga Islami, yang merangkum hampir $90 \%$ dari luas permukaan tubuh mereka. Hanya wajah, tangan, dan kaki yang terpapar saat mengenakan jenis olahraga ini. Banyak penelitian telah melaporkan bahwa pakaian yang diselimuti seluruh tubuh menghadirkan lebih banyak masalah termoregulasi untuk aktivitas fisik di lingkungan yang panas (Wijayanto, Fathna, \& Tochihara, 2016). 
Melihat semua keresahan yang terjadi penulis menciptakan sebuah desain jilbab, desain yang pertama (D1) dirancang dengan bahan utamanya adalahpoly-spandex fabrics memiliki sifat kain yang one way stretch, hampir mirip dengan katun hanya saja kain ini lebih tipis dan menyerap keringat. Desain yang ke 2 (D2) dirancang dengan kompenen utamanya adalah Spandex Balonfabrics Bahan ini merupakan hasil percampuran dari serat sintetis elastane dan serat polyester. Karakter yang dihasilkan dari kombinasi kedua serat kain ini yaitu sifat kain yang ringan, sangat lentur dan tampak mengkilat. Desain ke 3 (D3) dirancang dengan kompenen utamanya adalah Italian Lycra Fabrics Kain lycra bersifat fitting atau mengikut alunan tubuh pemakai sehingga bisa meregang hingga $80 \%$ (Mo'einfard, 2001). Selain bahannya yang ringan dan halus Italian Lycra Fabrics adalah salah satu kain yang tahan akan sinar ultraviolet sehingga pemakai akan tetap terjaga suhu tubuhnya.Sport Active Hijab dibuat dengan teknologi $X$-dry,dan Thermal Tech agar bisa membuat pemakai nya merasa bebas saat bergerak,tidak merasakan panas berlebih serta bisa mengurangi dehidrasi jangka pendek.

Perbedaan desain Sport Active Hijab dengan jilbab lainnya adalah terletak pada unsur bahan yang dipakai serta pemerhatian pola desain yang pada umumnya jilbab olahraga hanya memperhatikan ketebalan kain atau kelenturan kainnya saja. Sport Active Hijab menelusuri sifat sifat kain yang cocok untuk pemakaianya dalam cuaca apapun dan juga tetap membuat nyaman serta bebas bergerak saat melakukan aktivitas olahraga, juga memperhatikan dari sisi agama sebagaimana fungsinya agar pemakai tidak menampakan lekuk tubuh saat melakukan olahraga.

Sebagian besar mahasiswi FPOK beragama Islam dan banyak juga yang berprofesi sebagai atlet internasional maupun daerah. Ketika melaksanakan perkuliahan praktik khususnya mahasiswi Muslim, tidak memakai pakaian olahraga panjang dan tidak mengenakan jilbab karena merasa suhu badannya lebih panas dan lebih sering merasa dahaga begitu juga saat latihan. Berbeda saat melaksanakan perkuliahan teori, mereka lebih memilih memakai baju muslim (tertutup) dan mengenakan jilbab.

Sebuah penelitian harus dilakukan untuk membuktikan pengaruh dari pakaian olahraga wanita Muslim pada peningkatan suhu tubuh dan tingkat dehidrasi setelah berolahraga.

\section{METODE}

Sebelum melakukan penelitian eksperimen telah dilakukan uji rancang jilbab. Dirancang 3 jilbab untuk diujikan, desain mana yang dapat mempertahankan tingkat termoregulasi dan hidrasi tubuh setelah olahraga. Untuk mengetahui pengaruhnya peneliti harus membuktikan dalam sebuah penelitian. Menurut Sugiyono metode penelitian diartikan sebagai cara ilmiah untuk mendapatkan data dengan tujuan dan kegunaan tertentu. Beranjak dari sebuah permasalahan, rumusan masalah dan tujuan penelitian, maka metode yang akan digunakan dalam penelitian ini adalah metode eksperimen. Menurut Sugiyono metode penelitian eksperimen adalah metode penelitian yang digunakan untuk mencari pengaruh perlakuan tertentu terhadap yang lain dalam kondisi yang terkendalikan.

Dalam suatu penelitian perlu adanya suatu desain penelitian yang sesuai dengan variabelvariabel yang terkandung dalam tujuan dan hipotesis penelitian untuk diuji kebenarannya. Desain penelitian yang digunakan adalah pretest-posttest groups design, sampel melakukan pretest terlebih dahulu menggunakan jilbab yang biasa mereka pakai lalu di ukur tingkat termoregulasi dan hidrasi, kemudian melakukan postest menggunakan jilbab yang sudah di tentukan lalu kembali di ukur.

\subsection{Subjek Penelitian}

Subjek dalam penelitian ini sebanyak 15 orang mahasiswi FPOK UPI muslim dan berjilbab. Pemilihan populasi kepada mahasiswa Pendidikan Kepelatihan Olahraga UPI angkatan 2018. Populasi pada penelitian ini berjumlah 160 orang. Alasan peneliti memilih PKO 2018 sebagai populasi 
penelitian karena mahasiswanya $80 \%$ berstatus atlet, $40 \%$ mahasiswa nya adalah wanita, dan $30 \%$ dari jumlah mahasiswa wanitanya memakai jilbab. Hal ini memenuhi kriteria penelitian. Teknik sampling yang digunakan dalam penelitian ini adalah purposive sampling yaitu teknik penentuan sampel dengan pertimbangan atau penentuan kriteria tertentu.Adapun kriterianya adalah sebagai berikut:

1) Atlet wanita muslim.

2) Memakai jilbab dalam pelatihannya (olahraga).

3) Melakukan olahraga setiap hari (latihan).

4) Mempunyai IMT normal $(18,5-22,9)$.

5) Tidak mengonsumsi kafein, alkohol, dan merokok.

6) Tidak mengonsumsi obat-obatan dalam 3 hari terakhir sebelum pengukuran.

7) Tidak sedang mentsruasi.

\subsection{Prosedur Penelitian}

Setelah melakukan pemilihan sampel lalu sampel di bagi ke dalam 3 kelompok, sampel diharuskan meminum $500 \mathrm{ml}$ air 1 jam sebelum melakukan test, tidak diperbolehkan meminum minuman berwarna maupun berrasa 1 hari sebelum melakukan test dan tidak diperbolehkan memakan makanan yang mengandung zat pewarna alami ataupun buatan karena hal ini bisa sangat berpengaruh terhadap massa urin serta warna urin.

\section{HASIL PENELITIAN}

Data yang dihasilkan dalam penelitian ini merupakan data kuantitatif dari hasil pretest dan posttest kelompok uji desain, coba dan produk. Setelah diketahui perbedaan selisih dua mean dari dua sampel yang berpasangan dari subjek yang sama, dan setiap variabel diambil saat situasi dan keadaan yang berbeda. Peneliti melanjutkan untuk menguji ada atau tidaknya perbedaan rata-rata untuk lebih dari dua kelompok sampel yang tidak berhubungan. Jika ada perbedaan, rata-rata manakah yang lebih tinggi.

$\mathrm{H}_{\mathrm{o}}$ ditolak jika $\mathrm{P}$ value $>0,05$
$\mathrm{H}_{1}$ diterima jika $\mathrm{P}$ value $<0,05$

$\mathrm{H}_{0} \quad$ : Rata-rata antara kelompok Uji Desain, Coba dan Produk "berbeda"

$\mathrm{H}_{1} \quad$ : Rata rata antara kelompok Uji Desain, Coba, Produk "sama"

\begin{tabular}{ccccc}
\hline Kelompok & Data & $\begin{array}{c}\text { Asymp. } \\
\text { Sig }\end{array}$ & A & Keterangan \\
\hline $\begin{array}{c}\text { Uji Desain, } \\
\text { Coba, } \\
\text { Produk }\end{array}$ & Pretest & 0,547 & 0.05 & $\begin{array}{c}\mathrm{H}_{0} \text { ditolak } \\
\text { (sama) }\end{array}$ \\
\cline { 2 - 5 } & Postest & 0,015 & 0.05 & $\begin{array}{c}\mathrm{H}_{0} \text { diterima } \\
\text { (berbeda) }\end{array}$ \\
\hline
\end{tabular}

a. Hasil dari uji one way anova pretest termoregulasi kelompok uji desain, uji coba dan uji produk menunjukan nilai signifikansi sebesar 0,547 ( $\mathrm{p}>0.05$ ). Artinya $\mathrm{H}_{0}$ ditolak, hasil rata rata pretest kelompok uji desain, uji coba dan uji produk adalah sama.

b. Hasil dari uji one way anova postest hidrasi kelompok uji desain, uji coba dan uji produk menunjukan nilai signifikansi sebesar 0,015 $(\mathrm{p}<0.05)$. Artinya $\mathrm{H}_{0}$ diterima, hasil rata rata postest kelompok uji desain, uji coba dan uji produk adalah berbeda.

\begin{tabular}{|c|c|c|c|c|}
\hline Kelompok & Data & $\begin{array}{c}\text { Asymp. } \\
\text { Sig }\end{array}$ & A & Keterangan \\
\hline $\begin{array}{c}\text { Uji } \\
\text { Desain, } \\
\text { Coba, }\end{array}$ & Pretest & 0,630 & 0.05 & $\begin{array}{c}\text { tidak } \\
\text { terdapat } \\
\text { perbedaan }\end{array}$ \\
\hline Produk & Postest & 0,022 & 0.05 & $\begin{array}{l}\text { terdapat } \\
\text { perbedaan }\end{array}$ \\
\hline
\end{tabular}

a. Hasil dari uji one way anova pretest hidrasi kelompok uji desain, uji coba dan uji produk menunjukan nilai signifikansi sebesar 0,630 ( $p$ > 0.05). Artinya $\mathrm{H}_{0}$ ditolak, hasil rata rata pretest kelompok uji desain, uji coba dan uji produk adalah sama.

b. Hasil dari uji one way anova postest hidrasi kelompok uji desain, uji coba dan uji produk menunjukan nilai signifikansi sebesar 0,022 ( $\mathrm{p}<0.05$ ). Artinya $\mathrm{H}_{0}$ diterima, hasil rata rata pretest kelompok uji desain, uji coba dan uji produk adalah berbeda.

\section{PEMBAHASAN}

Setelah melihat semua faktor yang ada peneliti menguji 3 jilbab dengan desain yang berbeda, pada desain yang pertama dengan kompenen utama nya adalah kain poli-spandex. Desain dari D1 ini memang desain pertama yang 
peneliti rancang sehingga masih sangat banyak kekurangan dalam sisi pola. Saat pelaksanaan treatment dengan berolahraga kelompok 1 banyak mengeluhkan mengenai lingkar leher yang sedikit sempit, itu membuat mereka merasakan panas yang berlebih, hal ini di buktikan dengan data yang di dapat, pada D1 nilai skor termoregulasi adalah $\left(37,44{ }^{\circ} \mathrm{C}\right)$. Hal ini juga di buktikan pada uji t test 0,025 (2tailed) $<0.05$, maka $\mathrm{H}_{0}$ di terima. Artinya "tidak terdapat pengaruh yang signifikan dari pakaian olahraga Muslim SAH (Sport Active Hijab) desain D1 dalam mempertahankan tingkat termoregulasi tubuh setelah olahraga".Jika suhu tubuh diatas level normal maka itu berkaitan erat juga dengan level hidrasi, kelompok uji desain ini adalah kelompok yg menglami dehidrasi sedang dengan nilai skor hidrasi $(5,20)$. Hal ini dapat di buktikan pada uji t test 0,013 sig (2tailed) $<0,05$, maka $\mathrm{H}_{0}$ diterima artinya "tidak terdapat pengaruh yang signifikan dari pakaian olahraga Muslim SAH (Sport Active Hijab) desain D1 dalam mempertahankan tingkat hidrasi tubuh setelah olahraga". Maka jilbab desain D1 ini tidak berpengaruh dalam mempertahankan termoregulasi dan hidrasi tubuh.

Peneliti membandingkan dengan kelompok uji coba yang memakai desain D2, pola jilbabnya sudah di perbaiki tidak hanya memperhatikan sisi anatomisnya tapi peneliti memperhatikan juga sisi agama, karena dalam islam wanita tidak di perbolehkan memperlihatkan lekuk tubuh. Pola yang ke 2 ini di buat dengan penutup dada yang lebih panjang kompenen utama nya adalah spandex ballon bahannya lebih tipis dan dingin. Beberapa orang dalam kelompok ini mengeluhkan keringat pada bagian leher dan kepala memang terserap olehkain jilbab namun setelah beres olahraga merasakan bau, artinya kain ini tidak antibacterial. Ada yang mengeluhkan kulitnya mudah terpapar panas, karna sifat kainnya yang tipis jadi memudahkan transfer panas masuk kedalam. Karena sifat kainnya yang dingin dan sifat premeability lebih besar mengakibatkan suhu tubuh bisa lebih cepat menyesuaikan kembali dengan suhu tubuh asal. Nilai pengukuran termoregulasi pada kelompok ini adalah $\left(36.300{ }^{\circ} \mathrm{C}\right)$ ini termasuk kedalam level normal, ada peningkatan dari hasil kelompok desain. Hal ini juga di buktikan pada uji t test 0,132 (2-tailed) $>0.05$ maka $\mathrm{H}_{0}$ di tolak artinya "terdapat pengaruh yang signifikan dari pakaian olahraga Muslim SAH (Sport Active Hijab) desain D2 dalam mempertahankan tingkat termoregulasi setelah olahraga". Namun pada pengukuran hidrasi masih pada angka di bawah normal yaitu $(4,20)$ walaupun ada perbedaan tapi tidak signifikan. Hal ini dapat di buktikan dari uji $\mathrm{t}$ test $0,021 \mathrm{sig}$ (2-tailed)< 0,05, maka $\mathrm{H}_{0}$ diterima artinya "tidak terdapat pengaruh yang signifikan dari pakaian olahraga Muslim SAH (Sport Active Hijab) desain D2 dalam mempertahankan tingkat hidrasi tubuh setelah olahraga". Artinya jilbab desain D2 ini tidak berpengaruh dalam mempertahankan hidrasi tubuh.

Setelah mengevaluasi kekurangan nya peneliti menguji desain $\mathrm{d} 3$ dengan kompenen utamnya yaitu italian lycra yang disebut sebut adalah kain terbaik di dunia untuk pakaian salah satu nya pakaian olahraga. Kain lycra bersifat fitting atau mengikut alunan tubuh pemakai sehingga bisa meregang hingga 80\% (mo'einfard, 2001). "lycra keeping a normal level of bacteria on the skin offers a high level of comfort and personal hygiene, especially during athletic activities"(mo'einfard, 2001). Kelompok uji produk ini sama dengan 2 kelompok lainnya, sama sama melakukan olahraga dan melakukan syarat penelitian. Namun mereka tidak mengeluhkan mengenai hal yang sama seperti kelompok uji desain dan uji coba. Mereka hanya mengeluhkan pola yang menurut merekan kurang panjang pada bagian dada, tapi untuk yang lainnya tidak ada masalah. Dilihat dari fungsi kainnya talian lycra ini ultraviolet protect, paparan sinar matahari tidak akan langsung menembus mengenai kulit tapi akan di pantulkan kembali.

Setelah di dapatkan hasil termoregulasi dari kelompok ini di dapatkan hasil sebesar $\left(36.00{ }^{\circ} \mathrm{C}\right)$ sehingga desain D3 ini berhasil mempertahankan tingkat termoregulasi, sesuai dengan fungsional dari pola dan kain yang dibuat berpengaruh. Hal ini di buktikan juga pada uji $\mathrm{t}$ test 0,611 (2-tailed) $>0.05$ maka $\mathrm{H}_{0}$ di tolak artinya "terdapat pengaruh yang signifikan dari pakaian olahraga Muslim SAH (Sport Active Hijab) desain D3 dalam mempertahankan tingkat termoregulasi tubuh setelah olahraga". Lalu ketika di ketahui nilai skor status hidrasi dinyatakan normal (terhidrasi) dengan rata rata nilai $(2,80)$. Hal ini di buktika dengan uji $t$ test 0,374 (2-tailed) >0.05 maka $\mathrm{H}_{0}$ di tolak artinya "terdapat pengaruh yang signifikan dari pakaian olahraga Muslim SAH (Sport Active Hijab) desain D1 dalam mempertahankan tingkat hidrasi tubuh setelah olahraga". Tidak hanya termoregulasi desain ini juga berpengaruh 
terhadap tingkat hidrasi yang berhasil di pertahankan.

Berdasarkan penelitian dan pengolahan data yang dilakukan membuktikan bahwa terdapat pengaruh dari Sport Active Hijab dalam mempertahankan tingkat termoregulasi dan hidrasi tubuh setelah olahraga. Dari 3 desain yang peneliti rancang hanya 1 desain yang dapat mempertahankan termoregulasi dan hidrasi tubuh artinya yang layak pakai menurut hasil dari penelitian ini hanya 1 desain yaitu desain $\mathrm{d} 3$.

\section{KESIMPULAN DAN SARAN}

Berdasarkan hasil penelitian yang diperoleh dengan analisis data dan pengujian hipotesis, maka dapat ditarik kesimpulan sebagai berikut:

1) Tidak terdapat pengaruh yang signifikan dari pakaian olahraga Muslim SAH (Sport Active Hijab) desain (D1) dalam mempertahankan tingkat termoregulasi tubuh setelah olahraga. Diketahui nilai signifikansi nya adalah 0,025 (2-tailed) < 0.05 yang artinya terdapat perbedaan yang signifikan.

2) Tidak terdapat pengaruh yang signifikan dari pakaian olahraga Muslim SAH (Sport Active Hijab) desain (D1) dalam mempertahankan tingkat hidrasi tubuh setelah olahraga. Diketahui nilai signifikansi nya adalah 0,013 sig (2-tailed) $<0,05$ yang artinya terdapat perbedaan yang signifikan.

3) Terdapat pengaruh yang signifikan dari pakaian olahraga Muslim SAH (Sport Active Hijab) desain (D2) dalam mempertahankan tingkat termoregulasi tubuh setelah olahraga. Diketahui nilai signifikansi nya adalah 0,132 (2-tailed) $>0.05$ yang artinya tidak terdapat perbedaan yang signifikan.

4) Tidak terdapat pengaruh yang signifikan dari pakaian olahraga Muslim SAH (Sport Active Hijab) desain (D2) dalam mempertahankan tingkat hidrasi tubuh setelah olahraga. Diketahui nilai signifikansi nya adalah $0,021 \mathrm{sig}$ (2-tailed) $<0,05$ yang artinya terdapat perbedaan yang signifikan.

5) Terdapat pengaruh yang signifikan dari pakaian olahraga Muslim SAH (Sport Active Hijab) desain (D3) dalam mempertahankan tingkat termoregulasi tubuh setelah olahraga. Diketahui nilai signifikansi nya adalah 0,611 (2-tailed) > $0.05 \quad$ yang artinya tidak terdapat perbedaan yang signifikan.

6) Terdapat pengaruh yang signifikan dari pakaian olahraga Muslim SAH (Sport Active Hijab) desain (D3) dalam mempertahankan tingkat hidrasi tubuh setelah olahraga. Diketahui nilai signifikansi nya adalah 0,374 (2-tailed) $>0.05$ yang artinya tidak terdapat perbedaan yang signifikan.

\section{DAFTAR PUSTAKA}

Almatsier, Sunita, S. S. \& M. S. (2011). Gizi Seimbang dalam daur kehidupan. jakarta: PT Gramedia Pustaka Utama.

Amani, R. Z., Maulana, R., \& Syauqy, D. (2017). Sistem Pendeteksi Dehidrasi Berdasarkan Warna dan Kadar Amonia pada Urin Berbasis Sensor TCS3200 Dan MQ135 dengan Metode Naive Bayes. Pengembangan Teknologi Informasi Dan Ilmu Komputer, 1(5), 436-444.

Archer, D. T. (2013). Effects of method of dehydration on post exercise rehydration. Proceedings of the Nutrition Society, 72(OCE4), 2013. https://doi.org/10.1017/s0029665113003157

Ashadi, K. (2017). SUHU TUBUH LATIHAN EFFECT OF RELATIVE HUMIDITY ON BODY TEMPERATURE CHANGES, 5(1), 103-109.

Bompa, \& TO. (2015). Periodization Training for Sports: Theory and Methodology of Training. Fifth Edition. United State of America: Human Kinetic, 2(1), 1-10.

Brooks, G. A., Hittelman, K. J., Faulkner, J. A., \& Beyer, R. E. (2014). Temperature, functions, skeletal and oxygen muscle debt mitochondrial. American Journal of Physiology, 220(4), 10531059 .

Buanasita, A., \& Sulistyowati, I. (2015). Perbedaan Tingkat Konsumsi Energi, Lemak, Cairan, dan Status Hidrasi Mahasiswa Obesitas dan Non Obesitas (Difference of Consumption Level of Energy, Fat, Liquid and Hydration Status of Obese and Non Obese Students). Indonesian Journal of Human Nutrition, 2(1), 11-22. Retrieved from www.ijhn.ub.ac.id

Elektromedik, J. T. (2018). Uji Thermometer Suhu Tubuh Contact Dan Non Contact. 
Erianna., A. (2017). active for muslim women.

Faradilla, A., \& Putrianto, N. K. (2018). The Effect Of Clothes Material On The Human Psychological And Physiological Response While Exercising In Hot Environment, 07, 191-200.

Farahwahida, \& Afzan, N. (2016). Aurat wanita muslim menurut perspektif islam: penerimaan dan pengamalan di kalangan masyarakat. Utm, 11(March 2016), 1-7. Retrieved from http://eprints.utm.my/11656/1/Aurat_Wanita_Muslim_Menurut_Perspektif_Islam_Penerimaan. pdf

Foltz, B. D., \& Ferrara, J. (2017). dehydration hidden symptoms.

Frank E. Marino. (2008). Thermoregulation and Human Performance.

Hasibuan, R., Simanullang, R. J., Terhadap, M., Status, T., Cairan, H., Setelah, T., ... Pendahuluan, A. (2018). PENGARUH PEMBERIAN AIR KELAPA MUDA TERHADAP TINGKAT STATUS HIDRASI CAIRAN TUBUH SETELAH, 2(April), 42-51.

Haslegrave, C. M. (2008). antrhopometry, ergonomics and the design of work.

Kane, S. N., Mishra, A., \& Dutta, A. K. (2016). Preface: International Conference on Recent Trends in Physics (ICRTP 2016). Journal of Physics: Conference Series, 755(1), 6-10. https://doi.org/10.1088/1742-6596/755/1/011001

Kim, H., \& Na, H. (2014). A Study on Ergonomic Fashion Design - Focused on Body Conscious Active Sportswear -. Fashion \& Textile Research Journal, 16(3), 434-445. https://doi.org/10.5805/sfti.2014.16.3.434

Kraemer, W. J., Fry, A. C., Frykman, P. N., Conroy, B., \& Hoffman, J. (2016). Resistance Training and Youth. Pediatric Exercise Science, 1(4), 336-350. https://doi.org/10.1123/pes.1.4.336

Kukus, Y., Supit, W., \& Lintong, F. (2013). Homeostasis Dan Efek Terhadap Kinerja Tubuh Manusia. Jurnal Biomedik (Jbm), 1(2). https://doi.org/10.35790/jbm.1.2.2009.824

Leksana, E. (2015). Strategi Terapi Cairan pada Dehidrasi, 42(1), 70-73.

Mo'einfard, M. (2001). Sportswear Of Iranian Female Futsal Players And Their Satisfaction Rates, (5757), 1549-1557.

Neal, R. A., Corbett, J., Massey, H. C., \& Tipton, M. J. (2016). Effect of short-term heat acclimation with permissive dehydration on thermoregulation and temperate exercise performance. Scandinavian Journal of Medicine and Science in Sports, 26(8), 875-884. https://doi.org/10.1111/sms.12526

O'Brien, J., Stein, A., Harkness, G., \& Islam, S. (2018). Muslim Female Athletes and the Hijab. Gender, Sexuality, and Intimacy: A Contexts Reader, 76-77. https://doi.org/10.4135/9781506352299.n23

Pertiwi, D. (2015). Status Dehidrasi Jangka Pendek Berdasarkan Hasil Pengukuran Puri (Periksa Urin Sendiri) Menggunakan Grafik Warna Urin Pada Remaja. Acta Universitatis Agriculturae et Silviculturae Mendelianae Brunensis (Vol. 16). https://doi.org/10.1377/hlthaff.2013.0625

Prouse, C. (2015). Harnessing the hijab: the emergence of the Muslim Female Footballer through international sport governance. Gender, Place and Culture, 22(1), 20-36. https://doi.org/10.1080/0966369X.2013.832664

Ramadhan, R. I., \& Rismayanthi, C. (2005). Hubungan Antara Status Hidrasi Serta Konsumsi Cairan Pada Atlet Bola Basket. Medikora, VX(April), 53-69.

S. Arikunto. (2016). Metode Penelitian, 37-52.

Sandi, I. N. (2011). Pengaruh Suhu Dan Kelembaban Relatif Udara Terhadap Penampilan Fisik Dalam Olahraga., 282-287.

Santoso, B. I., \& Dkk. (2011). Air Bagi Kesehatan, 6(2), 54-60.

Shangold, M., \& Mirkin, G. (2016). Women and Exercise Physiology and Sports Medicine. Hahnemann University Philadelphia, Pennsylvania GABE.

Shirreffs, S. M. (2017). Markers of hydration status. European Journal of Clinical Nutrition, 57, S6S9. https://doi.org/10.1038/sj.ejen.1601895

Shirreffs, Susan M., Jéquier, E., Rosenberg, I., Sawka, M., Dal Canton, A., Manz, F., \& Armstrong, L. (2005). The importance of good hydration for work and exercise performance. Nutrition Reviews, 63(6 II). https://doi.org/10.1301/nr.2005.jun.S14-S21

Sugiyono. (2012). MetodePenelitian, 20-32.

Sugiyono. (2017). Sugiyono, Metode Penelitian. Penelitian, 34-45. https://doi.org/10.1021/ol7029646 tirto.id. (2018). Miftahul Jannah \& Perjuangan Atlet Berjilbab di Gelanggang Olahraga, 
6(November), 67-72.

Toffoletti, K., \& Palmer, C. (2017). New approaches for studies of Muslim women and sport. International Review for the Sociology of Sport, 52(2), 146-163. https://doi.org/10.1177/1012690215589326

Uttam, D. (2013). Active Sportswear Fabrics. International Journal of IT, Engineering and Applied Sciences Research (IJIEASR) Volume 2, No. 1, January 2013, 2(1), 2319-4413. Retrieved from www.irjcjournals.org

Van Rosendal, S. P., Osborne, M. A., Fassett, R. G., \& Coombes, J. S. (2009). Physiological and performance effects of glycerol hyperhydration and rehydration. Nutrition Reviews, 67(12), 690-705. https://doi.org/10.1111/j.1753-4887.2009.00254.x

Wijayanto, T., Fathna, M. F., \& Tochihara, Y. (2016). Physiological Responses During Exercise Wearing Women' S Islamic Sportswear in Warm Humid. ICHES 2016 The Fifth International Conference on Human-Environment System, (November 2016).

Yulikhah, S. (2017). ANTARA KESALEHAN DAN FENOMENA SOSIAL Safitri Yulikhah Wartawan metrosemarang . com Email : vitri.yulikha@gmail.com Abstract perempuanlah yang cenderung menjadi objek seks -baik karena struktur dengan pria . Hal ini karena sex appeal yang dimiliki perempua. Jurnal Ilmu Dakwah, 36, 96-117. 